\title{
Modeling Antarctic subglacial lake filling and drainage cycles
}

\author{
Christine F. Dow ${ }^{1, \text { a }}$, Mauro A. Werder ${ }^{2}$, Sophie Nowicki ${ }^{1}$, and Ryan T. Walker ${ }^{1,3}$ \\ ${ }^{1}$ Cryospheric Sciences Laboratory, NASA Goddard Space Flight Center, Greenbelt, MD, USA \\ ${ }^{2}$ Laboratory of Hydraulics, Hydrology and Glaciology (VAW), ETH Zurich, Zurich, Switzerland \\ ${ }^{3}$ Earth System Science Interdisciplinary Center, University of Maryland, College Park, MD, USA \\ ${ }^{a}$ now at: Department of Geography and Environmental Management, University of Waterloo, Waterloo, ON, Canada
}

Correspondence to: Christine F. Dow (christine.dow @uwaterloo.ca)

Received: 29 October 2015 - Published in The Cryosphere Discuss.: 25 November 2015

Revised: 31 May 2016 - Accepted: 13 June 2016 - Published: 8 July 2016

\begin{abstract}
The growth and drainage of active subglacial lakes in Antarctica has previously been inferred from analysis of ice surface altimetry data. We use a subglacial hydrology model applied to a synthetic Antarctic ice stream to examine internal controls on the filling and drainage of subglacial lakes. Our model outputs suggest that the highly constricted subglacial environment of our idealized ice stream, combined with relatively high rates of water flow funneled from a large catchment, can combine to create a system exhibiting slow-moving pressure waves. Over a period of years, the accumulation of water in the ice stream onset region results in a buildup of pressure creating temporary channels, which then evacuate the excess water. This increased flux of water beneath the ice stream drives lake growth. As the water body builds up, it steepens the hydraulic gradient out of the overdeepened lake basin and allows greater flux. Eventually this flux is large enough to melt channels that cause the lake to drain. Lake drainage also depends on the internal hydrological development in the wider system and therefore does not directly correspond to a particular water volume or depth. This creates a highly temporally and spatially variable system, which is of interest for assessing the importance of subglacial lakes in ice stream hydrology and dynamics.
\end{abstract}

\section{Introduction}

Subglacial lakes store large quantities of water in bedrock overdeepenings and regions of hydraulic convergence underneath the Antarctic ice sheets, including the highly dynamic ice streams (e.g., Wingham et al., 2006; Wright and Siegert, 2012). The role of these water bodies in ice dynam- ics is largely unknown and limited by availability of data and knowledge of the basal hydrological regimes. The former has been addressed with satellite surface altimetry data products, allowing analysis of surface ice flexure in the region of subglacial lakes (e.g., Gray et al., 2005; Fricker et al., 2007). It has been found that many of the lakes in regions of fast flowing ice are active over a period of $<1-5$ years causing ice uplift and subsidence related to the lake filling and draining (e.g., Fricker et al., 2010). In the case of Byrd Glacier in East Antarctica, the drainage of lakes has been found to cause significant downstream ice speed up over a period of 1-2 years (Stearns et al., 2008). Basal lakes also appear to be hydrologically interconnected. This is demonstrated by ice subsidence coincident with downstream ice uplift at lakes located $290 \mathrm{~km}$ apart in Adventure subglacial trench in the East Antarctic (Wingham et al., 2006). The mechanisms and longevity of hydrological connection are, however, not well understood.

In situ observations of hydrological conditions at the bed of the Antarctic ice sheets are limited due to difficulty of access. As an alternative, numerical models can be used to investigate the feedbacks between hydrology and subglacial lake formation. To date, hydrological models of Antarctic subglacial lakes have been primarily diagnostic rather than prognostic and rely on ice surface uplift and subsidence data to determine the threshold switch between lake filling and draining (Carter et al., 2009, 2011; Carter and Fricker, 2012). Pattyn (2008) used a synthetic approach with a full Stokes ice flow model to assess triggers for Antarctic lake drainage. Those model outputs suggested that small changes in water input into a lake can cause episodic, although partial, drainage and related changes in the ice surface slope. An ice 
flow modeling approach was also used by Sergienko et al. (2007) to assess changes in the ice surface slope and local dynamics due to lake drainage. That study found that changes in lake depth are not directly translated to ice surface uplift and subsidence so that assessing lake volume changes from ice surface altimetry is challenging. These ice dynamics models began to address the feedbacks between ice flow and subglacial lake filling and drainage, but did not include an active hydrological network, which is required to determine the larger, catchment-scale causes of lake stability.

Our primary aims are to examine (a) the hydrological conditions that allow subglacial lake growth and drainage on a catchment scale, and (b) the impact of the lake drainage on downstream water pressures and, by proxy, ice dynamics. To achieve this, we apply GlaDS, a finite-element basal hydrology model, to a synthetic system designed to represent an idealized Antarctic ice stream with one overdeepening. Using this simplified system allows us to identify hydrological controls on lake dynamics and examine the wider catchment without having to address the complications of highly variable basal topography. Our approach is novel as it does not require any external forcing to fill and drain the lakes (cf. Carter and Fricker, 2012); this instead occurs due to internal model dynamics. We begin, in Sect. 2, by giving a brief summary of the model and, in Sect. 3, our application of the model to the idealized ice stream. This is followed, in Sect. 4, by an exploration of the model outputs for an ice stream without and with an overdeepening, and the differences between the two setups. Section 5 gives an outline of results from sensitivity tests of the model and Sect. 6 covers the limitations of the modeling approach. We discuss the relevance and application of the model outputs in Sect. 7 before concluding in Sect. 8.

\section{GlaDS model}

GlaDS (Glacier Drainage System model) is a planview 2-D finite element model that incorporates equations for subglacial R-channel growth and linked cavity system development. It has previously been applied to simulate drainage systems of synthetic ice sheet catchments and real Alpine glaciers (Werder et al., 2013). The model configuration and application to synthetic ice sheet catchments and valley glacier systems is described fully in Werder et al. (2013); here we give a brief overview of the model. The effective pressure, $N$, in the system is

$N=P_{\mathrm{i}}-P_{\mathrm{w}}$,

where $P_{\mathrm{w}}$ is the water pressure and $P_{\mathrm{i}}=\rho_{\mathrm{i}} g H$ is the ice overburden pressure with $\rho_{\mathrm{i}}$ the ice density, $g$ the gravitational acceleration, and $H$ the ice thickness. Mass conservation in the distributed linked cavity system is described with

$$
\frac{\partial h}{\partial t}+\frac{\partial h_{\mathrm{e}}}{\partial t}+\nabla \cdot q=M
$$

Table 1. Model parameters.

\begin{tabular}{llll}
\hline Parameter & Symbol & Value & Units \\
\hline Ice flow constant & $A$ & $2.5 \times 10^{-25}$ & $\mathrm{~Pa}^{n} \mathrm{~s}^{-1}$ \\
Englacial void ratio & $e_{\mathrm{V}}$ & $10^{-5}$ & \\
Gravitational acceleration & $g$ & 9.81 & $\mathrm{~m} \mathrm{~s}^{-2}$ \\
Bedrock bump height & $h_{r}$ & 0.08 & $\mathrm{~m}$ \\
Latent heat of fusion & $L$ & $3.34 \times 10^{5}$ & $\mathrm{~J} \mathrm{~kg}^{-1}$ \\
Sheet width below channel & $l_{\mathrm{c}}$ & 2 & $\mathrm{~m}$ \\
Cavity spacing & $l_{r}$ & 2 & $\mathrm{~m}$ \\
Glen's flow constant & $n$ & 3 & \\
Basal sliding speed & $u_{\mathrm{b}}$ & 100 & $\mathrm{~m} \mathrm{a}^{-1}$ \\
Ice density & $\rho_{\mathrm{i}}$ & 910 & $\mathrm{~kg} \mathrm{~m}^{-3}$ \\
Water density & $\rho_{\mathrm{W}}$ & 1000 & $\mathrm{~kg} \mathrm{~m}^{-3}$ \\
\hline
\end{tabular}

where $h$ is the average thickness of the water layer, $h_{\mathrm{e}}$ is an effective storage layer thickness representing either an englacial or basal sediment aquifer, $q$ is the water discharge and $M$ is the prescribed source term for the distributed system representing, in this case, geothermal and frictional basal melt. Change in the water thickness is determined by cavity opening from sliding over basal bumps and closing through viscous ice deformation. Flux in the distributed system is related to the hydraulic potential gradient, $\phi=\rho_{\mathrm{w}} g B+P_{\mathrm{w}}$, where $\rho_{\mathrm{w}}$ is the water density and $B$ is the bed elevation. Channels are modeled as semi-circular R-channels that grow due to melting and close due to viscous creep of ice. Mass conservation in the channels is described with

$\frac{\partial S}{\partial t}+\frac{\partial Q}{\partial s}=\frac{\Xi-\Pi}{\rho_{\mathrm{w}} L}+m_{\mathrm{c}}$,

where $S$ is the channel cross-sectional area, $Q$ is the discharge through the channel, $s$ is the horizontal distance along the channel, $\Xi$ is the dissipation of potential energy, $\Pi$ represents the change in sensible heat, $L$ is the latent heat of fusion and $m_{\mathrm{c}}$ is the water that enters the channel from the surrounding distributed system. Model parameter values are given in Table 1 and follow the same nomenclature as in Werder et al. (2013).

The model mesh is unstructured with channels calculated along the element edges to form a network. Water is exchanged between channel segments at the element nodes. The distributed system is calculated within and across the elements. Interaction between the two hydrological systems is determined by assuming the water pressure is the same in a channel and the distributed sheet immediately adjacent to it. Crucially for our application to subglacial lake development, the pressure calculated in the distributed system also includes the water thickness so that a body of water, such as a lake, will have a direct impact on the system hydraulic potential. 
Table 2. Sensitivity test variables.

\begin{tabular}{lllll}
\hline Parameter & Symbol & Base value & Variations & Units \\
\hline Overdeepening depth & $D$ & 150 & 50,250 & $\mathrm{~m}$ \\
Sheet conductivity & $k$ & $1 \times 10^{-3}$ & $1 \times 10^{-4}, 1.1 \times 10^{-3}$ & $\mathrm{~m}^{7 / 4} \mathrm{~kg}^{-1 / 2}$ \\
Channel conductivity & $k_{\mathrm{c}}$ & $5 \times 10^{-2}$ & $5 \times 10^{-1}, 5 \times 10^{-3}$ & $\mathrm{~m}^{3 / 2} \mathrm{~kg}^{-1 / 2}$ \\
Sheet input & $M$ & 1 & $0.85,2$ & $\mathrm{~mm} \mathrm{a}^{-1}$ \\
\hline
\end{tabular}

\section{Model configuration}

We configure GlaDS to represent a synthetic Antarctic system with characteristics similar to Recovery Ice Stream in the East Antarctic ice sheet. Recovery Ice Stream has up to 13 active lakes that periodically fill and drain (Fricker et al., 2014). This system also has one of the largest catchments in the East Antarctic, draining $8 \%$ of the ice volume (Joughin et al., 2006), and is of considerable interest for analysis of lake drainage dynamics (Bell et al., 2007; Langley et al., 2011, 2014; Fricker et al., 2014). Our synthetic system is a simplified version of the Recovery region with a domain featuring a large catchment of area $5.4 \times 10^{5} \mathrm{~km}^{2}$ feeding into an ice stream of width $50 \mathrm{~km}$ and length $300 \mathrm{~km}$ (see Fig. 1). The total area of the upper catchment equals the Recovery subglacial drainage catchment area feeding into the ice stream. This was calculated using routing algorithms assuming water is at ice overburden pressure, applied to the BEDMAP2 basal and surface digital elevation models (DEMs) (Fretwell et al., 2013).

Two topographies are used within the model domain. The first has a planar basal slope of $0.06^{\circ}$. Due to the shallowing of ice surface slopes in the interior of Antarctic ice stream catchments, we construct a steeper surface slope of $0.29^{\circ}$ in the ice stream and $0.11^{\circ}$ in the catchment. These values are based on average surface slopes in Recovery Ice Stream and give a maximum ice thickness of $3337 \mathrm{~m}$. The second topography is identical to the first one except for an added overdeepening located $150 \mathrm{~km}$ upstream from the lower boundary. This overdeepening is created using a Gaussian formulation with a fixed radius of $7.5 \mathrm{~km}$ and maximum depth of $150 \mathrm{~m}$ overlain onto the basal planar slope; these values are consistent with medium-sized lakes in Recovery Ice Stream.

For the first topography, the model mesh in the ice stream has a minimum element edge length of $780 \mathrm{~m}$, which increases to an average edge length of $1500 \mathrm{~m}$ in the catchment. In the second topography the mesh is the same but is refined within the overdeepening to a minimum edge length of $220 \mathrm{~m}$, which allows accurate calculation of changes within the subglacial lake. We have performed tests to determine that results from our model runs are not dependent on the mesh configuration.

Water input to the distributed system is continuous across the domain, representing water production from both

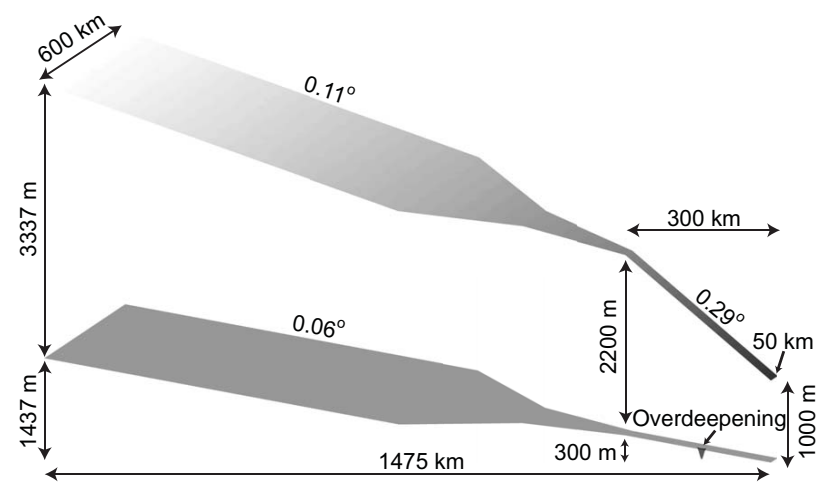

Figure 1. Model domain designed to emulate the catchment of Recovery Ice Stream. The overdeepening has a depth of $150 \mathrm{~m}$. The slopes of the planar surfaces are noted with a steeper surface slope in the narrow ice stream portion of the domain.

geothermal and frictional heating. Initially, we apply an input rate of $0.5 \mathrm{~mm} \mathrm{a}^{-1}$, a level that is likely too low for the Recovery region and is used to run the model to steady state. The second scenario uses the predicted water production rate for the Recovery catchment of $1 \mathrm{~mm} \mathrm{a}^{-1}$ (Fricker et al., 2014). The model is ramped from steady state to this level of water input over a period of 10 years, inducing a gradual change. In these model runs, the channel system has no direct input and channels are initiated from distributedbased flux; i.e., no pre-existing channels are assumed at the beginning of the model runs.

The upper and lateral boundary conditions are Neumann conditions set to zero inflow. The downstream boundary has a Dirichlet pressure condition set at ice overburden pressure to represent the ocean outlet of Recovery Ice Stream. Tidal influences on marginal water pressure are not included in this model set-up.

Our standard model parameters are listed in Table 1. Given lack of knowledge of the basal conditions in many regions of Antarctica, we perform sensitivity experiments to test the applicability of the model and also to assess controls on subglacial lake stability. These sensitivity parameters include tests on the overdeepening size, the conductivity of the distributed system versus the efficient system, and the volume of water produced at the bed. The variations of these parameters are given in Table 2. For each variation, the model is first al- 


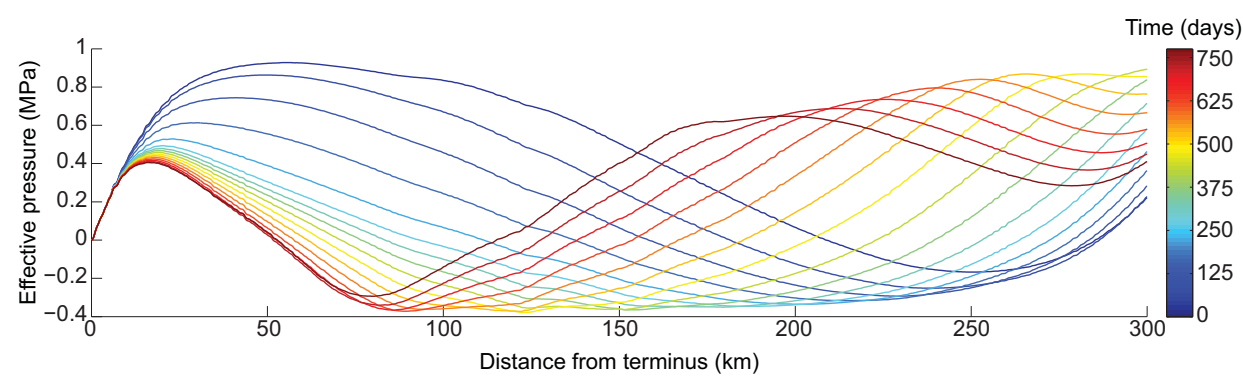

Figure 2. Effective pressure plotted for the ice stream in 50-day intervals, illustrating downstream movement of pressure waves. The outputs range from year 81 to 83 .

lowed to run to steady state. GlaDS is primarily set up to deal with distributed linked cavity systems. However, a sedimentbased distributed basal drainage system may behave in a similar fashion (Creyts and Schoof, 2009). By testing a range of conductivities in the distributed system we can emulate Darcian flow through sediment along with more conductive cavity-type systems. Sediment deformation and erosion processes, which could be important in ice stream hydrology and dynamics cannot, however, be taken into account with this model configuration.

\section{Results and analysis}

\subsection{Planar bed topography}

We begin by examining the hydrological development of the ice stream assuming no overdeepenings and a fully planar bed configuration. The steady state solution for our model with low water production throughout the system causes the model water pressure to drop below overburden everywhere, including to $75 \%$ of overburden within the ice stream. This low pressure occurs because there is not enough water to pressurize the distributed cavities for our fixed ice speed of $100 \mathrm{~m} \mathrm{a}^{-1}$. Antarctic systems likely operate close to overburden pressure due to the substantial ice thickness (Engelhardt and Kamb, 1997) and as a result, this steady state modeled solution is not realistic for the Recovery system.

In the second scenario, the water input rate is gradually increased over 10 years from steady state to that predicted for Recovery Ice Stream (i.e., $1 \mathrm{~mm} \mathrm{a}^{-1}$ ). The increased flux in the Recovery catchment initiates pressure waves in the ice stream where water is funneled from the large catchment into the narrower ice stream. We define a pressure wave as a ridge of water above ice overburden pressure, which propagates downstream. This is demonstrated in Fig. 2 where the change in effective pressure along the ice stream center line is plotted. In the Recovery system, these pressure waves repeat and by year 70 have settled into a periodic pattern as shown in Fig. 3a and b. This figure plots the average water pressure at locations 200 and $100 \mathrm{~km}$ from the margin, along with channel cross-sectional area. In these regions, the channels grow to $\sim 0.3 \mathrm{~m}^{2}$ and reduce to $<0.02 \mathrm{~m}^{2}$ crosssectional area over a pressure wave cycle. There is therefore a link between the pressure wave and the growth of channels. The pressure waves form because there is not enough hydrological capacity or hydraulic gradient at the bed of the ice stream to move water funneled from the large catchment downstream. The pressure of the water therefore increases, alters the hydraulic gradient and enhances downstream flux. This greater flux encourages growth of channels. Once the pressure wave has passed, flux rates decrease and the channels close. As a result, there are traveling waves of channel growth and shrinkage corresponding to the passage of the pressure waves.

Figure $3 \mathrm{c}$ shows effective pressure, $N$, along the center line for a series of pressure waves moving through the system. The pressure waves have, on average, a speed of $220 \mathrm{mday}^{-1}$ with an area of the domain remaining under pressures higher than overburden for up to 2 years. An example of one pressure cycle from year 85 to 88 is also plotted with the number of days the area is above overburden and the length scale affected by overpressure at that time (Fig. 3d). The longitudinal length affected by pressures above overburden varies on the timing of the wave cycle, increasing to a maximum of $\sim 170 \mathrm{~km}$ when the highest pressure is centered at a distance of $\sim 200 \mathrm{~km}$ from the downstream boundary of the ice stream (Fig. 3e). As a result, not all of the ice stream is equally affected by high pressures, both in terms of either the magnitude of the water pressure or its persistence.

\subsection{Overdeepened bed topography}

We now run the same set of experiments using the bed topography that includes an overdeepening. With the low water input forcing, a steady state solution is reached where the pressure is again entirely below overburden, including in the overdeepening. In this steady state, no lake forms in the overdeepening as the volume of water entering the overdeepening always equals the volume of water exiting. If the pressure in the hydrological system was everywhere at overburden pressure, as is commonly assumed when no hydrological modeling capability is available, all water flow would be directed into the overdeepening and form a lake. However, with 

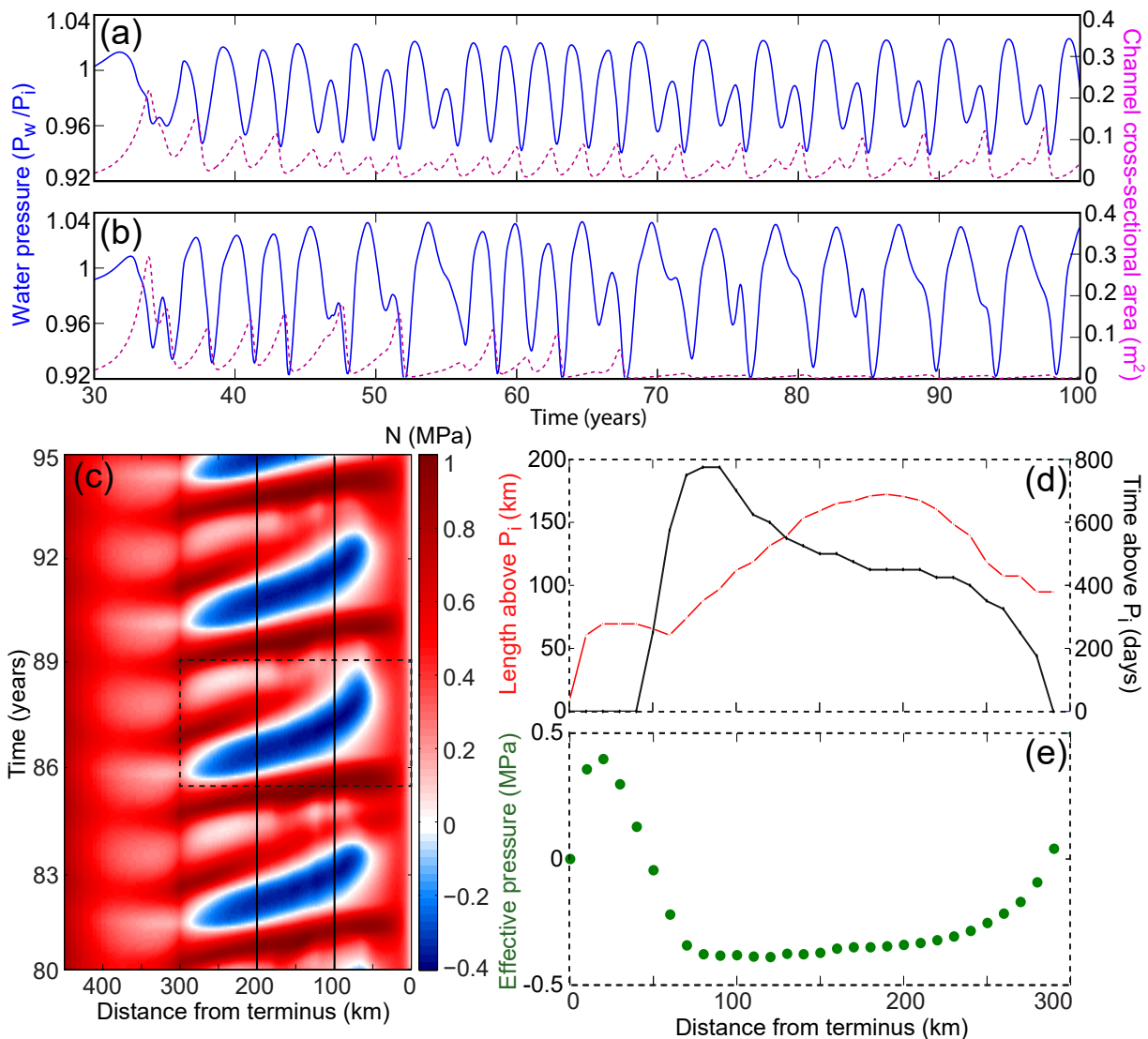

Figure 3. Model outputs from the system with no overdeepening. (a, b) Average water pressure (blue) and channel cross-sectional area (purple dashed) across the ice stream at a distance of 200 and $100 \mathrm{~km}$ from the front, respectively, corresponding to the solid black lines in (c). Prior to 30 years no pressure waves occur and so that time period is not plotted. (c) Time-distance plot of center line effective pressure demonstrating several pressure waves. The dashed box shows the feature analyzed in (d) and (e). (d) Longitudinal length affected by negative effective pressures at the time of pressure wave passing (red dashed curve) and the time of an area below negative effective pressure (black curve) along the ice stream. (e) Minimum effective pressure (green) along the ice stream.

a fully coupled hydrology model, the system adapts rapidly so that the pressure conditions in the lake are precisely at the level to allow equal outflow for inflow, with pressures slightly lower on the rim of the reverse slope than in the overdeepening so that there is a positive downstream hydraulic potential gradient despite the adverse slope. As a result, the overdeepening reverse slope does not prevent water flow through the lake.

Using the above steady state as the initial condition and then increasing the water input to the value representative of Recovery Ice Stream again causes pressure waves to occur (Fig. 4). The overdeepening slightly alters the timing of pressure waves compared to the planar model runs (compare Fig. $4 \mathrm{a}$ and $\mathrm{b}$ with Fig. 3a and b). However, the range of pressure change upstream of the overdeepening is similar between the planar and the overdeepening runs.

A lake forms in the overdeepening due to the altered hydraulic gradient from the pressure waves; the hydrological system cannot adjust rapidly enough to the increased wa- ter flux (Fig. 5). As the lake deepens, the hydraulic gradient over the reverse slope is steepened and water flux over the ridge is increased. This greater water flux allows channels to form on the downstream rim of the overdeepening and lake drainage occurs when the channels downstream of the lake are sufficiently developed to cause a steeper hydraulic potential gradient. Following lake drainage, water flux over the reverse slope slows and the downstream channels close (Fig. 5). The lake begins to form again when another pressure wave passes, changing the hydraulic potential and driving more water into the overdeepening.

Multiple lake drainages occur over a period of 100 years. As shown in Fig. 6, the lake does not always fill to the same volume prior to drainage, and it also has a variety of filling and drainage rates. On average, the maximum lake water depth and volume are $1.3 \mathrm{~m}$ and $0.86 \mathrm{~km}^{3}$, respectively. Once the lake has drained, the average lake depth is $0.47 \mathrm{~m}$ (Fig. 6a and c). The lake filling times range between $\sim 1$ and 3 years with an average of 1.65 years and drainage times between 
$\sim 0.8$ and 2.75 years, with an average of 1.8 years. The lake filling and drainage rates peak for each cycle at an average of $\sim 1$ and $1.5 \mathrm{~m}^{3} \mathrm{~s}^{-1}$, respectively. The fastest lake drainage rate is $2.3 \mathrm{~m}^{3} \mathrm{~s}^{-1}$ (Fig. 6d). The water pressure ranges between 0.95 and 1.04 as fractions of overburden (or 0.7 and $-0.6 \mathrm{MPa}$ effective pressure).

The changes in lake pressure do not always match the timing of lake growth and drainage and instead there is sometimes a pattern of two pressure waves for one lake drainage (Fig. 5). This is characterized by a pause in lake drainage as the pressure wave moves through the system, as illustrated by the lake depth plot in Fig. 5. The initial growth of the lake is driven by movement of the first pressure wave through the system. However, when the second wave moves through, the channels are sufficiently developed in the downstream region of the lake that they have capacity for the additional water driven into and out of the overdeepening. This channel capacity prevents the second pressure wave causing negative effective pressures downstream of the lake (Figs. 4c and 5). The pause in lake drainage is due to a combination of downstream channel pressurization and additional water flowing through the overdeepening. One lake drainage over two pressure wave cycles demonstrates that the pressure waves are not the only cause for lake growth and drainage but instead provide changing hydraulic conditions that prevent a steady state. As shown below in the sensitivity tests, the impact of the pressure wave on the lake growth and drainage timing depends on the conductivity of the system and the volumes of water in the hydrological networks.

Channel growth and shrinkage at the downstream margin of the lake are plotted in Fig. 7a along with the lake water level. During lake drainage, channels at the lake margin grow to a size of $\sim 0.07 \mathrm{~m}^{2}$, although $10 \mathrm{~km}$ downstream they temporarily increase to a maximum of $17 \mathrm{~m}^{2}$ (Fig. 7b). The channels are not always the same size when the lake drainage begins. One discernible pattern is that lower lake volumes at the end of drainage coincide with the smallest channel sizes. Beyond this, the rate of channel growth is also dependent on the pressure gradients downstream of the lake and on downstream channel size. As a result, exact controls for lake drainage timing are difficult to ascertain.

\section{Sensitivity results}

We tested the impact of overdeepening size on lake growth and drainage (Fig. 8a). When the overdeepening depth is decreased from 150 to $50 \mathrm{~m}$, very little water accumulates in the basin, with water depths increasing by $\sim 8 \mathrm{~cm}$ during a growth and drainage cycle. A deeper overdeepening of $250 \mathrm{~m}$ causes much greater water accumulation with lake depths up to $6 \mathrm{~m}$. The larger overdeepening also allows a lake to form and drain slightly more quickly compared to the lake in the standard overdeepening of $150 \mathrm{~m}$. If the overdeepening depth is increased to $500 \mathrm{~m}$, the model mesh is not locally refined enough to allow efficient running of the model and so for deeper lake configurations the model setup would have to be altered.

We also vary the volume of water produced at the bed. When the basal melt rate is decreased from 1 to $0.85 \mathrm{~mm} \mathrm{a}^{-1}$ there is a delay in onset of lake formation (Fig. 8b). The depth of the lake is also smaller than with the standard melt input at $<1 \mathrm{~m}$. For input rates smaller than $0.85 \mathrm{~mm} \mathrm{a}^{-1}$, no lakes form and no pressure waves occur. With water production rate doubled to $2 \mathrm{~mm} \mathrm{a}^{-1}$, lake drainages and pressure waves occur more frequently and initiate earlier, although the lake water levels fluctuate over a similar range. As $2 \mathrm{~mm} \mathrm{a}^{-1}$ is double the value of subglacial water production rates suggested for the Recovery catchment by Fricker et al. (2014) we do not test the model with greater rates of water production.

Lowering the distributed system conductivity from $1 \times 10^{-3}$ to $1 \times 10^{-4} \mathrm{~m}^{7 / 4} \mathrm{~kg}^{-1 / 2}$ causes a deeper lake to form, with lake growth and drainage occurring over a longer time scale (Fig. 8c). Lowering the conductivity further to $1 \times 10^{-5} \mathrm{~m}^{7 / 4} \mathrm{~kg}^{-1 / 2}$ causes the model to run too slowly to produce outputs over our analysis time period. When the conductivity is raised slightly from the baseline of $1 \times 10^{-3}$ to $1.1 \times 10^{-3} \mathrm{~m}^{7 / 4} \mathrm{~kg}^{-1 / 2}$, the lake takes longer to form than the standard run because the ice stream hydraulic capacity is larger; it therefore takes more time to reach near-overburden pressure and induce the pressure waves. With a higher distributed system conductivity, the system remains in steady state, no pressure waves develop, and no lake forms. There is therefore a narrow range of distributed system conductivities within which the lake will form and drain. However, combinations of different parameters also allow stable lake growth and drainage. For example, a higher distributed system conductivity with greater water input allows lake formation.

When channel conductivity is lowered from $5 \times 10^{-2}$ to $5 \times 10^{-3} \mathrm{~m}^{3 / 2} \mathrm{~kg}^{-1 / 2}$, no channels form at the margin of the lake and the pressure and lake level remain high throughout the model run (Fig. 8d). With a high channel conductivity of $5 \times 10^{-1} \mathrm{~m}^{3 / 2} \mathrm{~kg}^{-1 / 2}$, the system capacity of the ice stream is increased so pressure features do not occur; the ice stream is mostly in steady state and a lake does not form. In this situation, the lake water pressure stabilizes around $96 \%$ of overburden.

\section{Model limitations}

Our modeled synthetic system has limitations due to its simplified nature. For example, it does not incorporate variable topography, spatially varying basal melt rates, or variable basal sliding parameters. However, the aim with this model is to gain insight into lake filling and draining characteristics without complicating the system. It is possible that including topography in the model could impact the pressure waves and therefore the rates of lake filling and draining. We 

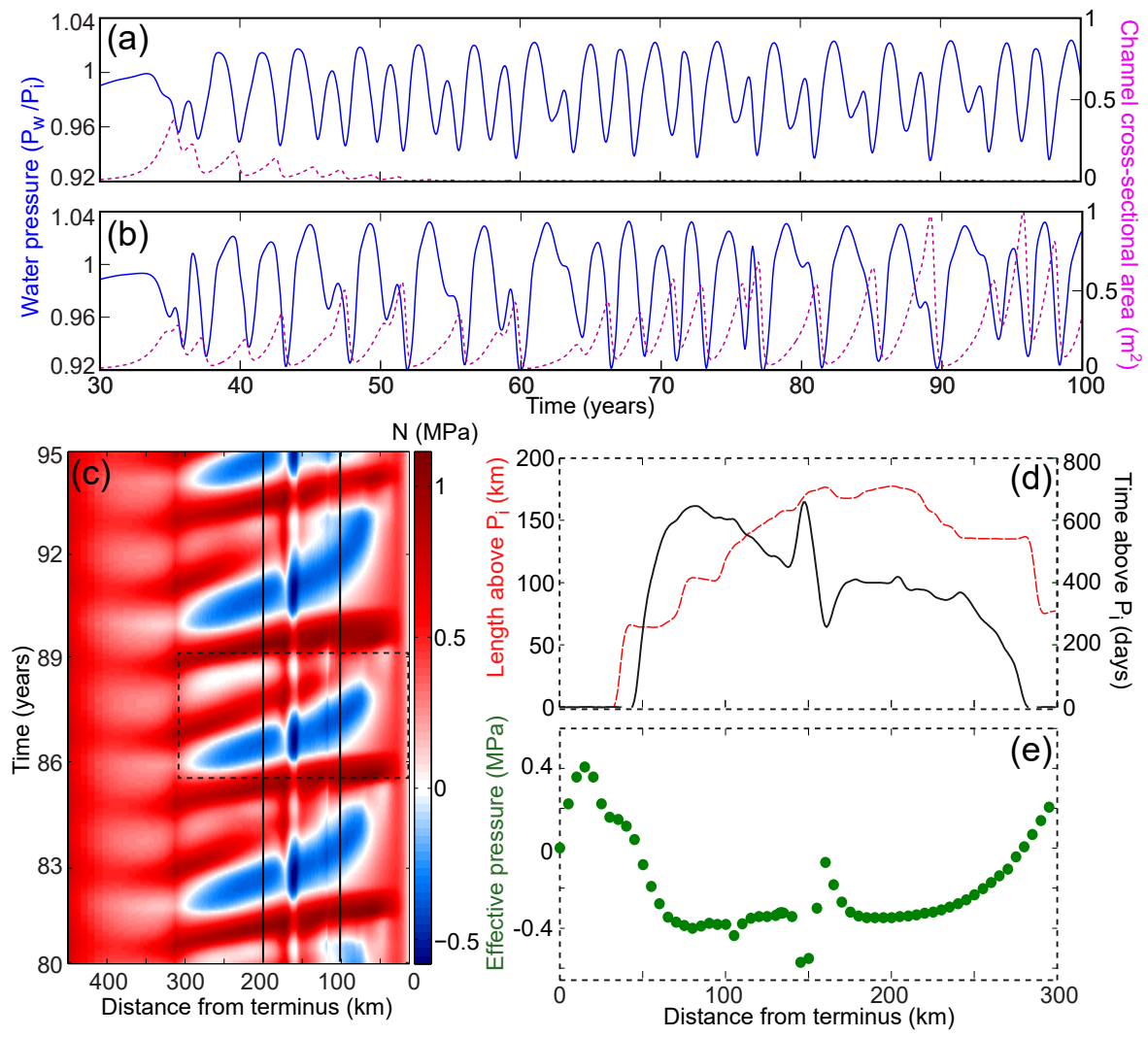

Figure 4. Model outputs from the system with the overdeepening. (a, b) Average water pressure (blue) and channel cross-sectional area (purple dashed) across the ice stream at a distance of 200 and $100 \mathrm{~km}$ from the front, respectively, corresponding to the solid black lines in (c). (c) Time-distance plot of center line effective pressure demonstrating several pressure waves. The dashed box shows the feature analyzed in (d) and (e). (d) Longitudinal length affected by negative effective pressures at the time of pressure wave passing (red dashed curve) and the time of an area below negative effective pressure (black curve) along the ice stream. (e) Minimum effective pressure (green) along the ice stream.

also assume that water flows through a linked cavity system rather than a sediment based system, with the latter possibly being more prevalent in Antarctic ice streams. Water flux in sediments could be more restricted than in linked cavity systems. However, it is plausible that sediment-based systems have similar dynamics as linked cavity networks with sliding opening spaces between the ice and substrate and ice creep closing the space when water pressures drop (Creyts and Schoof, 2009). Sediment deformation and erosion processes are, however, lacking in the model.

We have carefully conducted a series of tests to rule out, as far as possible, that the pressure wave features are numerical artifacts. We have performed tests to check that there is sufficient mesh convergence both in the planar and overdeepened topographies and obtain similar results as Werder et al. (2013) with differences in mean effective pressure and distributed water thickness on the range of $10^{-5}$ relative to a smaller mesh. The tolerances of the ordinary differential equation solver were also tested and selected accordingly.
Although likely not numerically induced, it is possible the pressure waves are not physical. The water pressures in the model do not exceed $1.04 \times P_{\mathrm{i}}$ (or $N=-0.5 \mathrm{MPa}$ ) and are therefore not unreasonable. However, pressures above overburden can persist in one area for up to 2 years, which is a long period of overpressure. Including ice dynamics in the model might change the characteristics of the pressure waves. Feedbacks through faster ice flow and coincident cavity opening could allow greater water flux downstream and reduction of water pressure, as is seen by Hewitt (2013). Ice physics such as those included in the models of Pattyn (2008) and Sergienko et al. (2007) where changing ice flux and ice surface slopes can influence lake drainage timing are also not incorporated into our model. It is therefore likely that more accurate predictions of lake filling and drainage require coupling of hydrology with ice dynamics models.

Including ice flexure and uplift could also impact the pressure waves and the rate of lake formation. For example, ice uplift at higher pressures could allow downstream flow of water to occur more rapidly than seen in the model, perhaps 


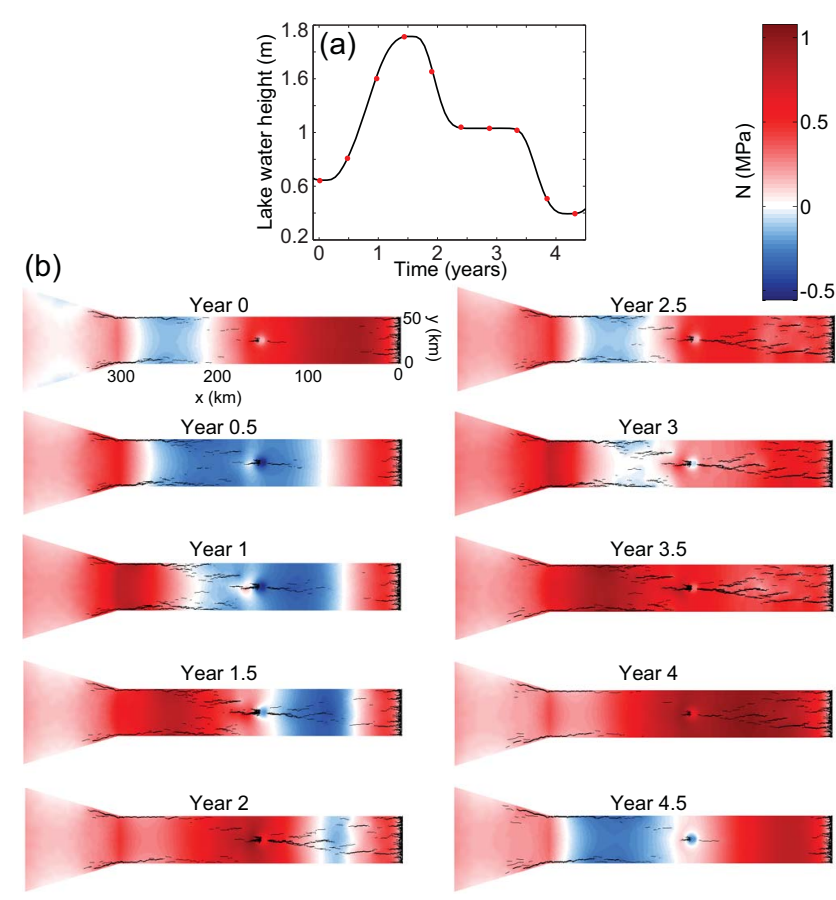

Figure 5. Changes in effective pressure in the ice stream (from years 48 to 52.5 ) over one lake filling and draining cycle, which occurs over two pressure wave cycles. (a) Lake water level (black curve) with pressure plot timing indicated by the red dots. (b) Pressure plots at six month intervals. Black lines indicate channels, with the line thickness illustrating channel size. The overdeepening is located $150 \mathrm{~km}$ from the terminus.

reducing local overpressure. However, given the propagation speed of the pressure waves and a viscous response time of ice on the order of months, it is unlikely that flexure would entirely remove the pressure waves; instead it might change the downstream speed of the wave. Future numerical experiments including ice flexure would provide insight into the likely persistence of the pressure waves observed in this hydrological model and the links between lake formation and the surface ice motion observed through satellite altimetry (e.g., Fricker et al., 2010).

Despite the limitations of the current model configuration, this is the first 2-D hydrological model to be applied to a synthetic system representing an Antarctic subglacial lake, which can produce lake drainage cycles through internal dynamics alone. The outputs therefore provide new insights and suggest directions of further research related to hydrological development and subglacial lake dynamics in Antarctic ice streams.

\section{Discussion}

Little is known about the spatial and temporal evolution of the subglacial meltwater drainage systems of Antarctica and their impacts on ice dynamics. With this hydrological mod- eling exercise we have produced outputs that suggest the system may be substantially different from that of the more closely studied mountain and Greenlandic outlet glaciers (e.g., Iken and Bindschadler, 1986; Nienow et al., 1998; Bartholomew et al., 2012; Dow et al., 2015). The Greenland Ice Sheet and mountain glaciers receive more than an order of magnitude more water volume per unit area from the surface than is produced at the bed of Antarctic ice streams through frictional and geothermal heating. In addition, in the Antarctic, variability in subglacial water pressure and fluxes likely does not occur on diurnal, weather-related, or seasonal timescales, but over years or even decades. These features cause two major difficulties when attempting to establish the characteristics of Antarctic subglacial hydrology: (1) estimates of subglacial water volumes are extrapolated from modeled geothermal heat fluxes and modeled basal friction from ice flux, rather than measured water inputs rates from the surface and (2) available data records, particularly from satellite sources, are limited to the last couple of decades. However, by applying a 2-D hydrology model, which produces lake filling and drainage through internal dynamics, we can make a step towards understanding and projecting the development of Antarctic subglacial drainage systems in addition to generating testable hypotheses.

\subsection{Pressure waves}

In mountain glaciers, much work has been dedicated to identifying development of efficient drainage networks that cause a decrease in ice velocity following a speed up at the beginning of the melt season when water enters an initially constricted system (e.g., Iken and Bindschadler, 1986; Röthlisberger and Lang, 1987; Schoof, 2010). In Greenland, a similar phenomenon has been identified near the ice sheet margin (e.g., Bartholomew et al., 2012; Cowton et al., 2013; Joughin et al., 2013). In the Antarctic, our hydrology model outputs suggest that funneling of water from a large catchment at the production rate expected for an ice stream like Recovery allows the water in the ice stream to flow continually at pressures close to and sometimes above overburden. Fast flow speeds in ice streams are strong evidence that this situation likely occurs in reality (e.g., Rignot et al., 2011). The growth of channels beneath the ice stream does diminish pressures but only to a level of $\sim 0.95 \times P_{\mathrm{i}}$ and therefore does not induce temporal changes in ice dynamics to the extent observed in mountain glaciers. However, growth of channels is a key enabler of spatially propagating pressure waves.

The pressure waves are an interesting phenomenon that has not been a common feature of glacial hydrology models. From our sensitivity tests we find that a combination of factors allow the waves to develop. These factors are: relatively low water fluxes; low hydraulic potential gradients due to shallow surface slopes; and funneling of water from a large catchment so that the water input rate is higher than the capacity of the ice stream. Our hydrological explanation for the 

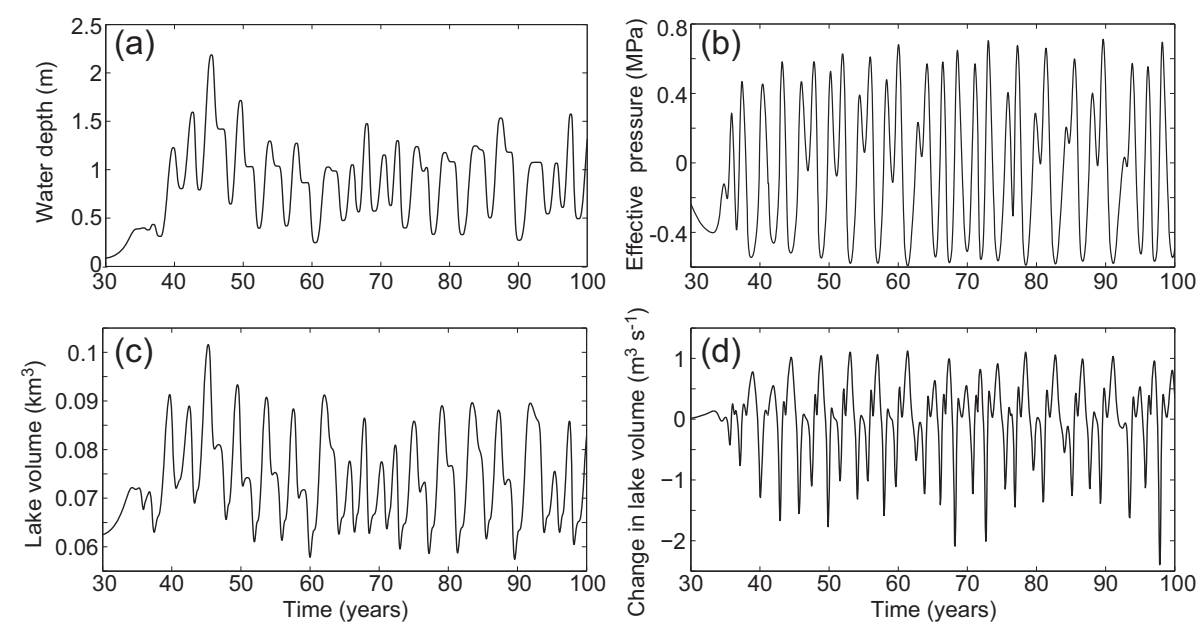

Figure 6. Conditions in the overdeepening over 100 years with (a) the maximum lake water depth, (b) the water effective pressure, (c) the volume of the lake in the overdeepening and (d) the filling (positive) and drainage (negative) rates of the lake.

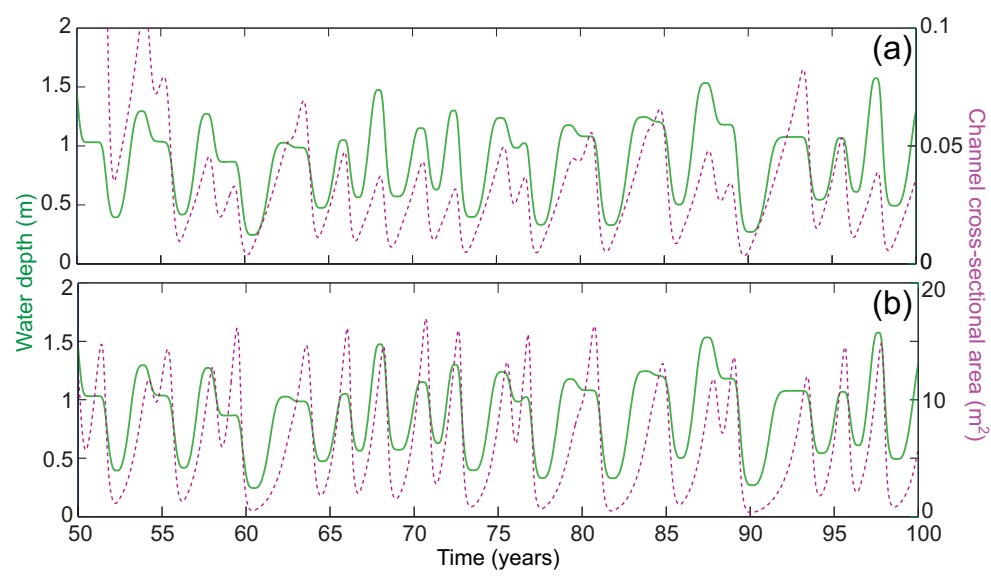

Figure 7. Maximum lake depth (green) and conduit cross-sectional area (purple dashed) at (a) the rim of the overdeepening adverse slope and (b) $10 \mathrm{~km}$ downstream from the overdeepening rim, over 50 years. Lake depth is the same in each plot for direct comparison with channel size.

waves is that water pressure builds up in the upper region of the ice stream, increasing the hydraulic gradient. This leads to faster water flow resulting in temporary channel growth, moving the excess water downstream. Despite the pressure change, the water layer thickness of the cavity system only increases by a maximum of $8 \mathrm{~cm}$, suggesting that it would be difficult to see passage of the pressure wave in surface elevation data. However, the regions affected by high water pressure could cause an increase in ice velocity that might be identifiable on the ice surface using feature tracking methods.

There is evidence from other glacial systems that transient regions of high pressure do arise in constricted systems. Borehole data from Schoof et al. (2014) demonstrate that transient pressure oscillations occurred during the winter in a glacier in the Yukon Territory of Canada. These were driven by low water flux rates in a constricted system. The oscillations lasted over a period of days, as opposed to years as seen in our model of Antarctic ice streams. Schoof et al. (2014) modeled this system on an idealized flowline and demonstrated that storage of water is an important control on the timing of internally driven oscillations. Given the significant differences between a mountain glacier and an Antarctic ice stream it is not surprising that system oscillations would occur at different periodicities. However, it is encouraging that field evidence exists of internally driven transience when the basal hydrological system is expected to be highly constricted. Surging glaciers provide further evidence of pressure waves. Interferometric analysis of the 1995 Bering Glacier surge in Alaska identified numerous "bullseyes" suggested to represent regions of surface uplift due to high pressure from water in a constricted system (Fatland and Lingle, 2002). This region remained under pressure for between 1 and 3 days as water moved downstream. Similar regions of temporary uplift were also observed on a 


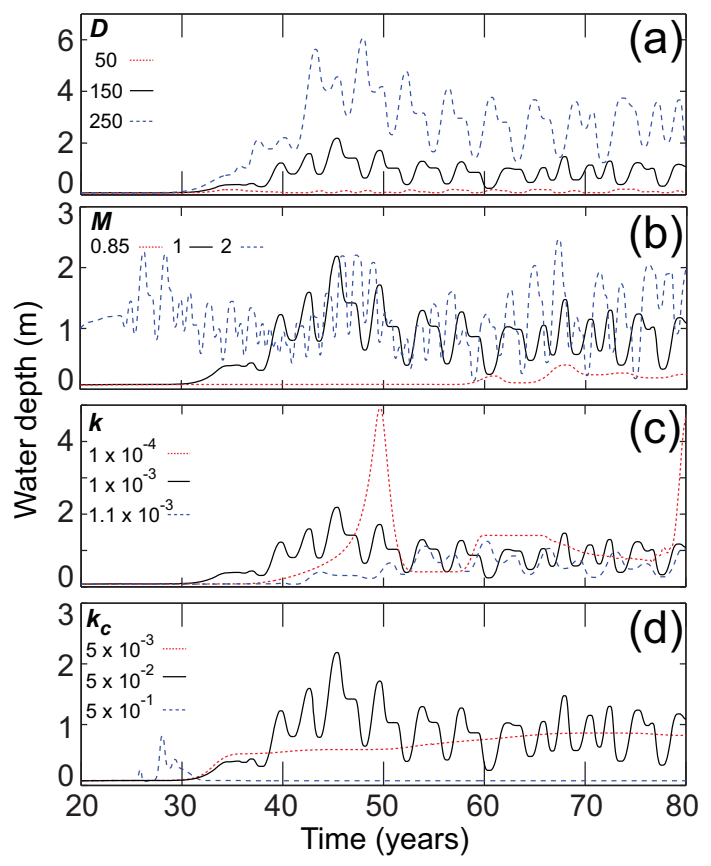

Figure 8. Maximum lake depth in the overdeepening from sensitivity testing. In each plot the black (solid) curve is the standard output. Tests of (a) overdeepening depth, $D(\mathrm{~m})$, (b) water input into the distributed system, $M\left(\mathrm{~mm} \mathrm{a}^{-1}\right)$, (c) distributed system conductivity $k\left(\mathrm{~m}^{7 / 4} \mathrm{~kg}^{-1 / 2}\right)$ and, (d) channel conductivity, $k_{\mathrm{c}}$ $\left(\mathrm{m}^{3 / 2} \mathrm{~kg}^{-1 / 2}\right)$.

nearby non surge-type glacier during the winter months when little water was moving through the system (Lingle and Fatland, 2003). Again, these pressure waves transit much more quickly than we suggest might occur in an Antarctic system but illustrate that such oscillations are observable in data.

\subsection{Subglacial lakes}

The hydrological model produces lake growth and drainage over a cumulative period of 2 to 4.5 years (Fig. 6). This cycle is driven by both the pressure waves and the growth of channels downstream of the lake. As such, the lake drains due to similar factors that characterize jökulhlaups in regions like Grímsvötn, Vatnajökull, in Iceland. The lake water accumulation in the latter type of system is driven by increased melt through volcanically induced heating. In these lakes, as the water builds up in the basin, some leakage seeds channel growth (e.g., Nye, 1976; Clarke, 1982). The "seal" preventing lake drainage can be broken when the lake is at positive effective pressures depending on development and pressurization of the system downstream of the lake (Fowler, 1999). The jökulhlaup model of Fowler (1999) is based on the existence of a region of reverse hydraulic gradient downstream of the lake, which migrates upstream as the lake grows and alters the effective pressure gradient. In our modeled subglacial lakes in the Antarctic, the lake pressure is important in that it changes the hydraulic potential gradient driving water over the reverse slope, but there is no physical "seal" of reverse hydraulic potential gradients. Instead, it is channel size and overall system hydraulic gradient driven by changes further downstream that allow the lake to drain (Fig. 5). In the synthetic Antarctic system, the lakes are not draining at the time of maximum pressure in the lake so that, while it is not fully realistic to not take account of ice flexure at times of water overpressure, it is not the overpressure alone that is causing lake drainage (Fig. 6). As shown in Fig. 5, one lake growth and drainage cycle can span two pressure waves. This is because the channels are efficient enough by the time the second pressure wave forms to conduct the extra water driven into and out of the overdeepening. The second pressure wave therefore dissipates once it reaches the overdeepening and the channels prevent negative effective pressures from developing downstream of the draining lake. The fact that the lake does not grow and drain every time a pressure wave passes is further evidence that the size of channels both immediately downstream of the lake and further downstream in the system (creating the necessary hydraulic gradients) are crucial for both lake growth and drainage. Our sensitivity tests with less conductive channels demonstrate that the lake does not drain without the growth and shrinkage of channels (Fig. 8d).

The lack of repeating cycles of lake growth and drainage is similar to the jökulhlaups modeled by Kingslake (2015). Based on the Nye (1976) equations, his model demonstrated that lake floods driven by different rates of meltwater input had characteristics including chaotic dynamics (where the initial conditions strongly control lake flood timing and cycles do not repeat). In our simulations we see situations where meltwater input (driven by the pressure waves) causes a lake growth and drainage closely linked to the passage of the wave (see years 65 to 73 in Fig. 6). As noted above, we also have some lake drainages spanning two pressure wave cycles. The lake growth and drainage characteristics are nonrepeating (Fig. 6a) even though, in the scenario without an overdeepening, the pressure wave settles into a stable pattern by 70 years (Fig. 3a and b). As a result, our outputs also suggest chaotic dynamics and demonstrate that this can be a condition of 2-D-modeled hydrological networks in addition to 1-D models.

One important characteristic of the subglacial lakes to note is that at no stage does the overdeepening in the current configuration fully prevent downstream flux of water over the reverse slope. The presence of a subglacial basin therefore only hampers water flux rather than preventing it. This is because the hydrological system is rarely static at overburden pressure. Instead, when the system approaches overburden, the development of pressure waves causes continual changes in water pressure. At all stages of the model runs, water can flow up the adverse slope of the overdeepening; this is because water pressures at the rim of the overdeepening are slightly below overburden due to the presence of small channels. Combined with higher pressures in the lake, this cre- 
ates a gradient that allows water to flow up the reverse slope (Werder, 2016). The relative difference between the pressure in the lake and at the top of the adverse slope is a key driver for how much water can exit the lake. In terms of lake dynamics, this process suggests that an instability must be present in the modeled system to allow lake growth and drainage. Otherwise, the system tends to steady state with equal inflow and outflow through the overdeepening, and no lakes form. In our modeled system, the instability is caused by the pressure waves that continually change the hydraulic gradients in the system.

Ice surface elevation data have been available from satellite-based sources such as ICESat and CryoSat2. These data have allowed identification of lake filling and draining cycles over the period of a decade in various regions of Antarctica (e.g., Gray et al., 2005; Wingham et al., 2006; Fricker et al., 2007, 2014). The longevity of lake volume change means that it is not yet possible to determine whether the somewhat chaotic nature of lake growth and drainage, as suggested by the model outputs, is also seen in nature. It will require continued data from CryoSat 2 and from systems such as ICESat2, due to launch in 2017, to extend the record and allow assessment of the system development over the next couple of decades.

The lake that forms in the overdeepening is meters thick rather than filling the basin to a depth of $150 \mathrm{~m}$. This has important implications for attempts to calculate Antarctic-wide estimates of water budgets that include active lakes. Carter et al. (2011) and Carter and Fricker (2012) modeled water budgets for the Siple Coast region of the West Antarctic using water flux across a hydraulic equipotential surface and lake filling and drainage rates inferred from satellite altimetry data. This approach assumed that all water was flowing at overburden pressure and that overdeepenings prevented downstream water flux as the lakes were filling. Carter and Fricker (2012) adapted their model to allow for "leaking" lakes that did not act as sinks but allowed throughflow of all water. This water budgeting method produced encouraging results linking the satellite altimetry data with estimated basal melt rates. Our model outputs suggest, however, that overdeepenings can allow downstream water flow at the same time as accumulating lakes, and also that varying water pressures in the system are important for lake growth and drainage. This could impact the rates of filling and drainage of the Siple Coast lakes examined by Carter et al. (2011) and Carter and Fricker (2012), and perhaps explain some of the discrepancies between modeled lake filling and drainage rate when compared with the rates inferred from altimetry.

Changes of lake water level in the range of meters are also consistent with rates of ice surface uplift observed from altimetry measurements over Recovery Ice Stream (Fricker et al., 2014). The area of our lake is $177 \mathrm{~km}^{2}$, located $150 \mathrm{~km}$ from the ice margin. It is therefore somewhat comparable in location to lakes Rec4 and Rec5 in Recovery Ice Stream (although these are both slightly larger in area at 220 and
$273 \mathrm{~km}^{2}$, respectively; Fricker et al., 2014). Lake Rec3 is $50 \mathrm{~km}$ downstream from these larger lakes and has an area of $60 \mathrm{~km}^{2}$. It is difficult to compare our model results directly with the Recovery system because the latter is made up of many lakes and has a complex basal topography (Fricker et al., 2014). However, cumulatively lakes Rec4 and Rec5 were suggested to have increased in volume by $0.33 \mathrm{~km}^{3}$ over 4 years. These then drained by $0.22 \mathrm{~km}^{3}$ at a rate of $3.7 \mathrm{~m}^{3} \mathrm{~s}^{-1}$. In contrast, lake Rec 3 drained by $0.07 \mathrm{~km}^{3}$ with a flux of $0.57 \mathrm{~m}^{3} \mathrm{~s}^{-1}$ over less than 2 years (Fricker et al., 2014). Our typical model outputs for an overdeepening with an area of $177 \mathrm{~km}^{2}$ and depth of $150 \mathrm{~m}$, yield lake growth of $\sim 0.05 \mathrm{~km}^{3}$ over 1.6 years at a rate of $\sim 1 \mathrm{~m}^{3} \mathrm{~s}^{-1}$ and drainage over 2 years at a maximum rate of $1.5 \mathrm{~m}^{3} \mathrm{~s}^{-1}$. As a result, our model outputs lie within the range of the larger and smaller Recovery lake filling and drainage rates, which gives us confidence in our results.

\subsection{Impact on ice dynamics}

The growth and shrinkage of channels in mountain glacier and Greenlandic systems have been directly connected to changes in ice velocity (e.g., Iken and Bindschadler, 1986; Bartholomew et al., 2012). These channels are argued to form only during the summer melt-season and persist for several months before shutting down over winter. In our modeled Antarctic system, however, channels can persist for a number of years. The largest channel in the run with no lake grows from 0.7 to $19.1 \mathrm{~m}^{2}$ over 4 years and then collapses back to $0.2 \mathrm{~m}^{2}$ in less than a year. The faster rate of shrinkage, relative to the rate of channel growth is a result of the non-linear creep of ice closing the channel once pressures drop below overburden. This is an extreme example of a temporary channel in the modeled system. Instead most channels grow to $\sim 0.4 \mathrm{~m}^{2}$ as the pressure wave migrates through the region. Although basal water is not produced in great volumes in these Antarctic systems, it is funneled from very large catchments into narrow ice streams and therefore provides a constant supply of water that, over many years, can cause channel growth. Basal catchments in Greenland are, on the other hand, at least an order of magnitude smaller, so water flux through these systems will be lower during the winter months. The influx of much higher volumes of water in the summer melt season in Greenland overwhelms any background hydrological system creating a much more temporally dynamic system. As a result, the situation of constant water supply allowing system development is limited to a time period of less than a year.

In our synthetic Antarctic system, due to the growth of channels during subglacial lake drainage, there are rarely negative effective pressures directly downstream of the lake at the time of drainage. Instead, the channels are of sufficient size to propagate the high water pressure to $\sim 50 \mathrm{~km}$ downstream of the lake. However, due to the pressure waves moving through the entire ice stream, there are occasions during 
lake growth when effective pressures are negative in the region around the lake, contributing to channel development on the rim of the reverse slope (Fig. 3). As a result, periods of high water pressure (and by proxy faster ice velocity) in the vicinity of the lake occur as the lake is growing rather than when it is draining; conversely, high water pressures due to lake drainage are found downstream. This complex dynamical signal could be challenging to identify in ice surface velocity records. However, given that few high temporal resolution velocity measurements have been made for areas like Recovery Ice Stream, it is possible that such high pressure features have not yet been identified.

\section{Conclusion}

We have presented a 2-D model of idealized Antarctic subglacial drainage evolution using a synthetic setup designed to represent a simplified Recovery Ice Stream and catchment with one overdeepening. Our analysis has been focused on the growth and drainage of a subglacial lake. The hydrological model incorporates both distributed and efficient drainage networks that develop internally.

Due to water influx from a large catchment into the relatively narrow ice stream, the system does not remain in steady state and pressure waves develop. Increases in pressure cause steepening of the hydraulic gradient, enhanced downstream flux, and growth of channels as the wave moves downstream. The speed of the pressure waves is $\sim 220 \mathrm{~m} \mathrm{day}^{-1}$. Following passage of the water pressure peak, the channels shut down due to lack of water flux and pressures drop to levels slightly below overburden. Pressures can persist at such levels even in areas of thick ice because of the fast ice speed in the ice stream $\left(100 \mathrm{~m} \mathrm{a}^{-1}\right.$ in our model runs) continually opening basal cavities.

Our model reproduces lake growth and drainage over similar scales to those observed beneath Antarctic ice streams. Flux out of the lake is possible at all times due to sufficiently steep hydraulic potential gradients, although full lake drainage occurs only when channels at the adverse slope become large enough to conduct most of the water from the overdeepening. These channels grow due to a combination of slow flux out of the lake and the pressure waves, although lake drainage is not always tied to the timing of the pressure waves.

The results from this synthetic ice stream hydrological experiment suggest that the Antarctic basal systems can be highly transient and variable with interactions between water pressure and channel growth that occur over a scale of years. These results encourage further analysis of Antarctic ice stream velocities, which could show an imprint of such a system. Future work will involve applying this model to Recovery Ice Stream using realistic topography in addition to adding in ice flexure and ice dynamic components to the model setup.
Acknowledgements. Christine F. Dow was supported with a NASA Postdoctoral Program fellowship at the Goddard Space Flight Center, administered by Oak Ridge Associated Universities through a contract with NASA. Ryan T. Walker was funded by NASA grant NNX12AD03A. Sophie Nowicki acknowledges the support of the NASA Cryosphere Program. We thank Martin Sharp and an anonymous reviewer for their valuable input.

Edited by: R. Bingham

\section{References}

Bartholomew, I., Nienow, P., Sole, A., Mair, D., Cowton, T., and King, M. A.: Short-term variability in Greenland Ice Sheet motion forced by time-varying meltwater drainage: Implications for the relationship between subglacial drainage system behavior and ice velocity, J. Geophys. Res., 117, F03002, doi:10.1029/2011JF002220, 2012.

Bell, R. E., Studinger, M., Shuman, C. A., Fahnestock, M. A., and Joughin, I.: Large subglacial lakes in East Antarctica at the onset of fast-flowing ice streams, Nature, 445, 904-907, 2007.

Carter, S. P. and Fricker, H. A.: The supply of subglacial meltwater to the grounding line of the Siple Coast, West Antarctica, Ann. Glaciol., 53, 267-280, 2012.

Carter, S. P., Blankenship, D. D., Young, D. A., Peters, M. E., Holt, J. W., and Siegert, M. J.: Dynamic distributed drainage implied by the flow evolution of the 1996-1998 Adventure Trench subglacial lake discharge, Earth Planet. Sc. Lett., 283, 24-37, 2009.

Carter, S. P., Fricker, H. A., Blankenship, D. D., Johnson, J. V., Lipscomb, W. H., Price, S. F., and Young, D. A.: Modeling 5 years of subglacial lake activity in the MacAyeal Ice Stream (Antarctica) catchment through assimilation of ICESat laser altimetry, J. Glaciol., 57, 1098-1112, 2011.

Clarke, G. K. C.: Glacier Outburst Floods from 'Hazard Lake' Yukon Territory, and the Problem of Flood Magnitude Prediction, J. Glaciol., 28, 3-21, 1982.

Cowton, T., Nienow, P., Sole, A., Wadham, J., Lis, G., Bartholomew, I., Mair, D., and Chandler, D.: Evolution of drainage system morphology at a land-terminating Greenlandic outlet glacier, J. Geophys. Res.-Ea. Surf., 118, 29-41, 2013.

Creyts, T. T. and Schoof, C. G.: Drainage through subglacial water sheets, J. Geophys. Res.-Ea. Surf., 114, F04008, doi:10.1029/2008JF001215, 2009.

Dow, C. F., Kulessa, B., Rutt, I. C., Tsai, V. C., Pimentel, S., Doyle, S. H., van As, D., Lindbäck, K., Pettersson, R., Jones, G. A., and Hubbard, A.: Modeling of subglacial hydrological development following rapid supraglacial lake drainage, J. Geophys. Res.-Ea. Surf., 120, 1127-1147, doi:10.1002/2014JF003333, 2015.

Engelhardt, H. and Kamb, B.: Basal hydraulic system of a West Antarctic ice stream: constraints from borehole observations, J. Glaciol., 43, 207-230, 1997.

Fatland, D. R. and Lingle, C. S.: InSAR observations of the 199395 Bering Glacier (Alaska, USA) surge and a surge hypothesis, J. Glaciol., 48, 439-451, 2002.

Fowler, A.: Breaking the seal at Grímsvötn, Iceland, J. Glaciol., 45, 506-516, 1999.

Fretwell, P., Pritchard, H. D., Vaughan, D. G., Bamber, J. L., Barrand, N. E., Bell, R., Bianchi, C., Bingham, R. G., Blankenship, 
D. D., Casassa, G., Catania, G., Callens, D., Conway, H., Cook, A. J., Corr, H. F. J., Damaske, D., Damm, V., Ferraccioli, F., Forsberg, R., Fujita, S., Gim, Y., Gogineni, P., Griggs, J. A., Hindmarsh, R. C. A., Holmlund, P., Holt, J. W., Jacobel, R. W., Jenkins, A., Jokat, W., Jordan, T., King, E. C., Kohler, J., Krabill, W., Riger-Kusk, M., Langley, K. A., Leitchenkov, G., Leuschen, C., Luyendyk, B. P., Matsuoka, K., Mouginot, J., Nitsche, F. O., Nogi, Y., Nost, O. A., Popov, S. V., Rignot, E., Rippin, D. M., Rivera, A., Roberts, J., Ross, N., Siegert, M. J., Smith, A. M., Steinhage, D., Studinger, M., Sun, B., Tinto, B. K., Welch, B. C., Wilson, D., Young, D. A., Xiangbin, C., and Zirizzotti, A.: Bedmap2: improved ice bed, surface and thickness datasets for Antarctica, The Cryosphere, 7, 375-393, doi:10.5194/tc-7-3752013, 2013.

Fricker, H. A., Scambos, T., Bindschadler, R., and Padman, L.: An active subglacial water system in West Antarctica mapped from space, Science, 315, 1544-1548, 2007.

Fricker, H. A., Scambos, T., Carter, S., Davis, C., Haran, T., and Joughin, I.: Synthesizing multiple remote-sensing techniques for subglacial hydrologic mapping: application to a lake system beneath MacAyeal Ice Stream, West Antarctica, J. Glaciol., 56, 187-199, 2010.

Fricker, H. A., Carter, S. P., Bell, R. E., and Scambos, T.: Active lakes of Recovery Ice Stream, East Antarctica: a bedrockcontrolled subglacial hydrological system, J. Glaciol., 60, 10151030, 2014.

Gray, L., Joughin, I., Tulaczyk, S., Spikes, V. B., Bindschadler, R., and Jezek, K.: Evidence for subglacial water transport in the West Antarctic Ice Sheet through three-dimensional satellite radar interferometry, Geophys. Res. Lett., 32, L03501, doi:10.1029/2004GL021387, 2005.

Hewitt, I. J.: Seasonal changes in ice sheet motion due to melt water lubrication, Earth Planet. Sc. Lett., 371, 16-25, 2013.

Iken, A. and Bindschadler, R. A.: Combined measurements of subglacial water pressure and surface velocity of Findelengletscher, Switzerland: conclusions about drainage system and sliding mechanism, J. Glaciol., 32, 101-119, 1986.

Joughin, I., Bamber, J. L., Scambos, T., Tulaczyk, S., Fahnestock, M., and MacAyeal, D. R.: Integrating satellite observations with modelling: basal shear stress of the Filcher-Ronne ice streams, Antarctica, Philos. T. Roy. Soc. Lond. A, 364, 1795-1814, 2006. Joughin, I., Das, S. B., Flowers, G. E., Behn, M. D., Alley, R. B., King, M. A., Smith, B. E., Bamber, J. L., van den Broeke, M. R., and van Angelen, J. H.: Influence of ice-sheet geometry and supraglacial lakes on seasonal ice-flow variability, The Cryosphere, 7, 1185-1192, doi:10.5194/tc-7-1185-2013, 2013.

Kingslake, J.: Chaotic dynamics of a glaciohydraulic model, J. Glaciol., 61, 493-502, 2015.
Langley, K., Kohler, J., Matsuoka, K., Sinisalo, A., Scambos, T., Neumann, T., Muto, A., Winther, J.-G., and Albert, M.: Recovery Lakes, East Antarctica: Radar assessment of sub-glacial water extent, Geophys. Res. Lett., 38, L05501, doi:10.1029/2010GL046094, 2011.

Langley, K., Tinto, K., Block, A., Bell, R., Kohler, J., and Scambos, T.: Onset of fast ice flow in Recovery Ice Stream, East Antarctica: a comparison of potential causes, J. Glaciol., 60, 1007-1014, 2014.

Lingle, C. S. and Fatland, D. R.: Does englacial water storage drive temperate glacier surges?, Ann. Glaciol., 36, 14-20, 2003.

Nienow, P., Sharp, M., and Willis, I.: Seasonal changes in the morphology of the subglacial drainage system, Haut Glacier d'Arolla, Switzerland, Earth Surf. Proc. Land., 23, 825-843, 1998.

Nye, J. F.: Water flow in glaciers: jökulhlaups, tunnels and veins, J. Glaciol., 17, 181-207, 1976.

Pattyn, F.: Investigating the stability of subglacial lakes with a full Stokes ice-sheet model, J. Glaciol., 54, 353-361, 2008.

Rignot, E., Mouginot, J., and Scheuchl, B.: Ice flow of the Antarctic ice sheet, Science, 333, 1427-1430, 2011.

Röthlisberger, H. and Lang, H.: Glacial Hydrology, chap. GlacioFluvial Sediment Transfer: An Alpine Perspective, John Wiley and Sons, New York, 207-284, 1987.

Schoof, C.: Ice-sheet acceleration driven by melt supply variability, Nature, 468, 803-806, 2010.

Schoof, C., Rada, C. A., Wilson, N. J., Flowers, G. E., and Haseloff, M.: Oscillatory subglacial drainage in the absence of surface melt, The Cryosphere, 8, 959-976, doi:10.5194/tc-8-959-2014, 2014.

Sergienko, O., MacAyeal, D., and Bindschadler, R.: Causes of sudden, short-term changes in ice-stream surface elevation, Geophys. Res. Lett., 34, L22503, doi:10.1029/2007GL031775, 2007.

Stearns, L. A., Smith, B. E., and Hamilton, G. S.: Increased flow speed on a large East Antarctic outlet glacier caused by subglacial floods, Nat. Geosci., 1, 827-831, 2008.

Werder, M. A.: The hydrology of subglacial overdeepenings: a new supercooling threshold formula, Geophys. Res. Lett., 43, 2045 2052, doi:10.1002/2015GL067542, 2016.

Werder, M. A., Hewitt, I. J., Schoof, C. G., and Flowers, G. E.: Modeling channelized and distributed subglacial drainage in two dimensions, J. Geophys. Res.-Ea. Surf., 118, 2140-2158, 2013.

Wingham, D. J., Siegert, M. J., Shepherd, A., and Muir, A. S.: Rapid discharge connects Antarctic subglacial lakes, Nature, 440, 1033-1036, 2006.

Wright, A. and Siegert, M.: A fourth inventory of Antarctic subglacial lakes, Antarct. Sci., 24, 659-664, 2012. 